\title{
A Smart Board Approach in Teaching Engineering Mathematics Course
}

\author{
Sri Vinodhini $\mathrm{H}^{1}$, Julius Fusic $\mathrm{S}^{2}$, Bhagyalakshmi $\mathrm{P}^{3}$ \\ ${ }^{1}$ Department of Mathematics, Thiagarajar College of Engineering, Madurai, Tamilnadu. \\ ${ }^{2,3}$ Department of Mechatronics Engineering, Thiagarajar College of Engineering, Madurai, Tamilnadu \\ ${ }^{1}$ srivinodhini@tce.edu \\ for the subject tends to infinity when the subject introduces \\ an abstract definition and ideas. Drawing graphs, figures,
}

\begin{abstract}
Technological world of today is emerging out day by day with lots of new innovation in the field of Education that adds essence to the pedagogical tools. Student-centric learning becomes more effective by adopting various innovative content delivery methods and assessment tools. Smart Board approach helps the instructor to adopt innovative content delivery style and use assessment tools that effectively measures student's learning ability. Using Smart Board to teach Engineering Mathematics II helps to kindle the interest in students for the subject by virtually presenting them the model to which the topic is correlated. Formative assessment is made enjoyable and effective through ICT tools like Think Pair Share, Plickers cards, Polls using Smart Board. This study is made to measure the impact of Smart Board Method in teaching Engineering Mathematics II on academic performance. The study was conducted on the students of second semester for the course Engineering Mathematics II. For this, a unit in Engineering Mathematics II, Vector calculus is chosen. Performance in formative assessment by the students who are taught using traditional black board approach and the students who are taught using Smart Board is analysed using Sampling Technique. The study summaries that the academic performance of graduates shall be greatly enhanced by improving formative assessment by implementation of Smart Board Method to teach Engineering Mathematics II.
\end{abstract}

Keywords: Smart board method, sampling technique, Engineering Mathematics, formative assessment.

\section{Introduction:}

Today, the pedagogical methods have extended its dimension more in virtual direction. Students of today expects virtual application of context they study to get better understanding. Gone are the days where students were not much into the virtual world. But millennium students of today, being highly exposed to virtual world, feel more interesting to learn the context through virtual world applications. Being a faculty of Mathematics, it is quite challenging to make the subject interesting to the students. The difficulty of an instructor to gain attention of the students diagrams etc to explain the context in a black board, helps students to visualize the idea. This is made more attractive and interactive with the help of Smart Board. The first basic advantage in using Smart Board is that we can solve quite a number of lengthy problems without erasing, as we can add pages to our worksheet. Another student friendly advantage in using smart board is that we can save the worksheet as portable document format (PDF) and the same can be shared with students for study purpose. This helps a faculty to maintain his/ her course material file in an easy way. As smart board provides us with browsing facility, one of the major advantages that an instructor and student could enjoy and avail to the maximum extent. This facility helps a faculty to virtually present an example to the students for the topic under study. This virtual approach tends to increase interest in students and keeps them active in class. Even an abstract idea like transformations, calculus is also made virtual with the help of this greatest facility that the smart board provides us with. The greatest advantage in using smart board is that it helps in making formative assessment more effective. At the end of class, the level of knowledge acquired by students is evaluated using ICT tools like Plickers cards, slido with the help of Smart Board. An interactive assessment is also made possible through tools like Think Pair Share. In this way, in-class activities are made interesting, more interactive and attention grabbing with this Smart Board environment. Usage of Learning management system like Moodle makes formative assessment through quiz is more effective and reduces time consumption in evaluating answers scripts. This study is carried out with an intention to measure the impact in usage of these emerging pedagogical tools in teaching Engineering Mathematics II. The impact is measured by the effectiveness in the performance by the students in formative assessment test.

\section{Sri Vinodhini H,}

Department of Mathematics, Thiagarajar

College of Engineering, Madurai.

srivinodhini@tce.edu

\section{Related work:}


In current scenario, many universities practicing ICT based learning to implement learner-centric based approach among technical courses.

The traditional learning approach had many draw backs which are highlighted is in many researches. From nineteenth century onwards, implantation of western education approach was introduced. The education system in India slowly evolved to International standards, social and professional growth among the stack holders. In $21 \mathrm{st}$ century the introduction of many gadgets and tools to improvise the interaction among the mentor \& student learning approach in engineering courses. For example, the Interactive board and mobile based learning approach using LMS platform paved a way to improvise the teaching learning process. The engineering education relying on availability of interactive way of lecturing the students and facilitate them to solve complex engineering problems. Over and above, the Emblematic engineering college mathematics instruction encompasses black board based instructional delivery that appeals to learners.

Charoula Angeli (2004) stated that the case-based learning approach of ICT tool in pedagogical use in classroom. The implementation of ICT tool in learning classroom provided an interactive way of teaching learning process. M Prince (2004) instructed that students need some reasonable interaction or discussion type of in class activity to learn concept clearly. Thus, the meaningful activity conducted inside classroom by mentor and facilitator paved the way to develop various active learning activities for students. The combination of ICT in education must be based on fundamental factors like access, creation, collection and connection of the contents. However, the adoption of active learning techniques in engineering courses for in-class activity has been slow. Lattuca et al. (2014) stated, to improve the Active learning activity for students, at first the faculty members need to progress their skills to engage students and develop interactive activities for their courses. P. D. Leedy et.al, (2005) detailed about the implementation of various skill development activity that engage students. The introduction of active learning strategy advanced the students to develop their qualitative skills which made them to convert traditional approach to gain marks into advance their knowledge and skills in specific course in engineering. Linda et.al, (2020) discussed about the Active learning strategies required some degree of intentional course planning activities. While implementing Active learning techniques with various strategies like instructor strategies, facilitator strategies to reduce the student resistance and interest in engineering courses. Even though multiple strategies were available in engineering platform, the execution of cognitive variability to solve problems in analytical courses were quite complicated. Many researchers focused on the strategy to solve complex cognitive problems especially when it comes to mathematics- based courses as stated in one of the researches works by Heinze et.al (2009). Christos Markopoulos (2010) demonstrated that the geometrical based problems followed many strategies like visual and conceptual 3D objects are complex cognitive processes to encode and decode spatial information. The introduction of interactive white board or smart board-based problem solving and graphical representation provide another dimension to solve complex engineering problems. The online and in class activity was done using interactive white board followed two broad patterns as problem solving pattern and organizer pattern. The problem-solving pattern used the teacher to solve problems virtually. The organizer pattern engaged the student to stimulating reflection and mathematical contributions.

In the proposed research paper, discusses in detail about course design and course planning for learner-centric approach, In class and Out class activities on Engineering Mathematics-II course. The result discussed the formative assessment data for analysing self-efficacy and innovative way of knowledge development in cognitive blooms level.

\section{Methodology:}

This study has used quantitative data analysis method to study the impact of smart board in formative assessment test. A unit titled Vector Calculus in the common course Engineering Mathematics II has been chosen in second semester of B.E/B.Tech programme offered by Thiagarajar College of Engineering, Madurai, India. From the detailed syllabus designed for this course by the institute, the course outcomes measured in this unit and its weightage for this course is given in Table: 1 .

Table 1. Course Outcome of the unit and it's weightage

\begin{tabular}{|c|l|c|}
\hline CO & \multicolumn{1}{|c|}{ Course Outcome Statement } & $\begin{array}{c}\text { Weightage } \\
\text { in \% }\end{array}$ \\
\hline CO1 & $\begin{array}{l}\text { Compute the Laplace transform } \\
\text { and inverse Laplace transform of } \\
\text { different functions }\end{array}$ & $10 \%$ \\
\hline CO2 & $\begin{array}{l}\text { Solve the given initial value problem } \\
\text { using Laplace transform }\end{array}$ & $15 \%$ \\
\hline CO3 & $\begin{array}{l}\text { Apply matrix algebra techniques } \\
\text { for transformations of conic } \\
\text { sections into principle axes }\end{array}$ & $\begin{array}{l}\text { Solve the model developed for the } \\
\text { given system using ordinary } \\
\text { differential equation }\end{array}$ \\
\hline CO5 & $\begin{array}{l}\text { Compute divergence and curl of } \\
\text { vector functions }\end{array}$ & $25 \%$ \\
\hline CO6 & $\begin{array}{l}\text { Apply the concepts of vector } \\
\text { differentiation and vector } \\
\text { integration to fluid flow and heat } \\
\text { transfer problems. }\end{array}$ & $10 \%$ \\
\hline
\end{tabular}

These course outcomes are measured in cognitive domain. Out of these course outcomes, CO5 and CO6 in Table: 1 is addressed by the unit that we have proposed to study in this article. CO5 and CO6 are in apply level. The assessment patten of this course is given in Table:2. The attainment level of these course outcomes is measured before and after implementation of Smart Board approach. From a population of 780 second semester students, a sample of 60 
students, from Mechatronics branch is chosen. The formative assessment includes 50 marks, in which 40 marks is calculated from best two out of three written continuous assessment tests conducted periodically and 10 marks from average of three assignments/quizzes/tutorials assigned Journal of Engineering Education Transformations, Volume

, No, Mont

regularly. The summative assessment is a written exam for 100 marks, which is calculated for 50 marks.

Table:2 - Cognitive level assessment pattern of the course Engineering Mathematics-II

\begin{tabular}{|c|c|c|c|c|c|c|c|}
\hline \multirow{2}{*}{$\begin{array}{c}\text { Cognitive } \\
\text { Levels }\end{array}$} & \multicolumn{3}{|c|}{$\begin{array}{c}\text { Continuous } \\
\text { Assessment } \\
\text { Tests }\end{array}$} & \multicolumn{3}{c|}{ Assignment } & \multirow{2}{*}{$\begin{array}{c}\text { Termin } \\
\text { al }\end{array}$} \\
\cline { 2 - 8 } & 1 & 2 & 3 & 1 & 2 & 3 & \\
\hline Remember & 10 & 10 & 10 & - & - & - & 10 \\
\hline Understand & 30 & 30 & 30 & - & - & - & 20 \\
\hline Apply & 60 & 60 & 60 & 100 & 100 & 100 & 70 \\
\hline Analyse & - & - & - & - & - & - & - \\
\hline Evaluate & - & - & - & - & - & - & - \\
\hline Create & - & - & - & - & - & - & - \\
\hline
\end{tabular}

This study is carried out with two consecutive batches of the students in the same course. As the course is taught by the schedule designed in course plan of the course in Table:3. The syllabus is divided into three equal parts and one third of the syllabus is prescribed for each continuous assessment test. By course plan given in Table:3, the topic under study is prescribed for Continuous Assessment test III and Assignment III. Hence, the experiment is conducted on third continuous assessment test and third assignment test. Sample I is the group who are taught using traditional black board method. The concepts of Divergence and Curl of a Vector field, Line Integrals, Surface Integrals are taught by giving examples orally and by explanatory diagrams drawn in black board. As the examples are visualised imaginarily, the students tend to lose interest. Some of the students might find difficult to visualize the example or diagram that is drawn in black board. They are asked quiz in class; they are given problems to solve as assignment to evaluate them as a part of formative assessment. They are evaluated based on their understanding level of the concept, methods applied in solving problem and the output. Sample II is the experimental group who are taught using Smart Board. The same concepts that are taught to Sample I is taught to Sample II by showing examples virtually. The rotational effect in curl, flux integral under surface integral are explained using real life problems, virtually with the help of Smart Board. This sets a good, colourful and virtual ambience, which in turn kindled the interest of students enabling them to learn more efficiently. Formative assessment of Sample II is done with the help of activities that involves usage of smart board.

Black board method approach to Sample I, though traditional, has few problems that are addresses in Smart Board approach. Problems on Surface Integral, Stoke's theorem are quite lengthy. While solving them in blackboard method, we solve the problem until the board is full. Once full, we wait for the students to copy the problem. After the students copied, we erase the board and continue to solve the problem. This breaks the continuity in solving the problem. Also makes it difficult for faculty to refer back to steps that are erased. During a class, the previous day 2015, ISSN 2349-2473, eISSN 2394-1707

problem and activities can only be recalled and have to write again if left unsolved. This problem is easily addressed by using smart board. As the user can add multiple pages to worksheet, the necessity to erase problems is rectified. The worksheet can be saved and taken for use again anytime. This helped to have continuity in problems and topics that are discussed in previous class. The worksheet is saved as PDF and the same is shared with students. This PDF is filed for preparing course file. This supported teachers to a great extent. At the end comes the major advantage in using Smart Board. After introducing and teaching the concepts of divergence, curl students are evaluated to know their understanding level using think pair share, plickers cards, slido. This made the students learn actively, discuss effectively and come up with their doubts for clarification in a healthy way. The assessment made by these activities does not add marks to formative assessment. But they highly influenced their performance in assignment, quiz, continuous assessment test that are part of formative assessment.

Table:3 - Course Plan of Engineering Mathematics II

\begin{tabular}{|c|c|c|c|}
\hline $\begin{array}{l}\text { Module } \\
\text { No. }\end{array}$ & Topic & $\begin{array}{c}\text { No. } \\
\text { Of } \\
\text { Hours }\end{array}$ & $\begin{array}{l}\text { Course } \\
\text { Outcome }\end{array}$ \\
\hline 1. & LAPLACE TRANSFORMS & & \\
\hline 1.1 & $\begin{array}{l}\text { Laplace Transform. Linearity. First } \\
\text { Shifting Theorem ( } s \text {-Shifting) }\end{array}$ & 2 & CO1 \\
\hline 1.2 & $\begin{array}{l}\text { Transforms of Derivatives and } \\
\text { Integrals. ODEs }\end{array}$ & 2 & $\mathrm{CO} 2$ \\
\hline 1.3 & $\begin{array}{l}\text { Unit Step Function (Heaviside } \\
\text { Function). } \\
\text { Second Shifting Theorem ( } t \text {-Shifting) }\end{array}$ & 1 & $\mathrm{CO} 1$ \\
\hline 1.4 & $\begin{array}{l}\text { Short Impulses. Dirac's Delta Function. } \\
\text { Partial Fractions }\end{array}$ & 1 & $\mathrm{CO} 1$ \\
\hline 1.5 & Convolution. Integral Equations & 2 & $\mathrm{CO} 2$ \\
\hline 1.6 & $\begin{array}{l}\text { Differentiation and integration of } \\
\text { transforms }\end{array}$ & 1 & $\mathrm{CO} 1$ \\
\hline 2 & $\begin{array}{l}\text { MATRICES EIGEN VALUE } \\
\text { PROBLEMS }\end{array}$ & & \\
\hline 2.1 & $\begin{array}{l}\text { Determining Eigenvalues and } \\
\text { Eigenvectors }\end{array}$ & 2 & $\mathrm{CO} 3$ \\
\hline 2.2 & $\begin{array}{l}\text { Some Applications of Eigenvalue } \\
\text { Problems }\end{array}$ & 1 & $\mathrm{CO} 3$ \\
\hline 2.3 & $\begin{array}{l}\text { Symmetric, Skew-Symmetric, and } \\
\text { Orthogonal Matrices }\end{array}$ & 2 & $\mathrm{CO} 3$ \\
\hline 2.4 & Eigenbases. Diagonalization. & 2 & $\mathrm{CO} 3$ \\
\hline 2.5 & Quadratic Forms & 2 & $\mathrm{CO} 3$ \\
\hline 3 & $\begin{array}{l}\text { ORDINARY DIFFERENTIAL } \\
\text { EQUATION }\end{array}$ & & \\
\hline 3.1 & $\begin{array}{l}\text { Homogeneous Linear ODEs of Second } \\
\text { Order }\end{array}$ & 2 & $\mathrm{CO} 4$ \\
\hline 3.2 & $\begin{array}{l}\text { Homogeneous Linear ODEs with } \\
\text { Constant Coefficients }\end{array}$ & 1 & $\mathrm{CO} 4$ \\
\hline 3.3 & Euler-Cauchy Equations & 1 & $\mathrm{CO} 4$ \\
\hline 3.4 & $\begin{array}{l}\text { Existence and Uniqueness of } \\
\text { Solutions. Wronskian }\end{array}$ & 1 & $\mathrm{CO} 4$ \\
\hline 3.5 & Nonhomogeneous ODEs & 2 & $\mathrm{CO} 4$ \\
\hline
\end{tabular}




\begin{tabular}{|c|l|c|l|}
\hline 3.6 & Solution by Variation of Parameters & 2 & CO4 \\
\hline $\mathbf{4}$ & VECTOR CALCULUS & & \\
\hline 4.1 & $\begin{array}{l}\text { Divergence and Curl of a Vector } \\
\text { Field }\end{array}$ & 2 & $\mathrm{CO} 5$ \\
\hline 4.2 & Line Integrals & 2 & $\mathrm{CO6}$ \\
\hline 4.3 & Green's Theorem in the Plane & 1 & $\mathrm{CO6}$ \\
\hline 4.4 & Surface Integrals & 1 & $\mathrm{CO6}$ \\
\hline 4.5 & $\begin{array}{l}\text { Triple Integrals. Divergence } \\
\text { Theorem of Gauss }\end{array}$ & 1 & $\mathrm{CO} 6$ \\
\hline 4.6 & $\begin{array}{l}\text { Applications of the Divergence } \\
\text { Theorem }\end{array}$ & 1 & $\mathrm{CO6}$ \\
\hline 4.7 & Stoke's Theorem & 1 & $\mathrm{CO6}$ \\
\hline & Total No. of Hours & 36 & \\
\hline
\end{tabular}

Students take up three Continuous Assessment

Tests each out of 50 marks and they are given three

Assignments either as descriptive test or quiz or in any other mode. For this study, marks scored by students of Sample I and Sample II out of 50 marks in Continuous Assessment Test III and Assignment Test III is taken as it's the data that support our analysis. From the marks obtained, the attainment level of the course outcomes under study is measured and analysed.

In traditional assignment method, all the students of Sample I received same set of questions for their Assignment III. In this case students tend to copy and assignment. As its copied, the percentage of students who scored below $50 \%$ is quite low. Even after that, the lag to learn things. As a result, when the same syllabus is proposed for Continuous Assessment Test III, students who copied assignment found difficult to score even the minimum required $50 \%$ marks. This increased the percentage of students with marks below $50 \%$. In this way, there is very low correlation between the marks obtained in Assignment Test III and Continuous Assessment Test III.

In Smart Board approach this correlation increases quite positively. As mentioned earlier, through smart board, day to day learning activity is improved and this influenced student of Sample II to learn actively. Through LMS Moodle, a different set of assignment and quiz is assigned to different group of students. Among the groups, each student will be assigned different questions. This enabled them to discuss and learn through integrity. In this case copying is restricted to maximum level. The scores obtained by the student reflected his knowledge in the context of study. This score was considered as their Assignment Test III marks. In this case, the deviation in the proportion of students below 50\% marks in Assignment Test III and Continuous Assessment Test III is quite low. This made students to make attempt and score genuinely to quite a good extent. The Rubric considered for evaluating Continuous Assessment test is given in Table: 6 . The rubric considered for evaluation is same for both samples. The same rubric is followed in evaluating assignment if given in descriptive mode. The smart board approach helps in improving the marks of the student by gradually improving each criterion in rubric framed.

Table:4 - Rubric for evaluating problems on Apply level in CO5 and $\mathrm{CO6}$

\begin{tabular}{|l|l|l|}
\hline S.No & Description & $\%$ of Marks \\
\hline
\end{tabular}

\begin{tabular}{|c|c|c|}
\hline 1. & $\begin{array}{c}\text { Identification of the Problem and } \\
\text { Formula }\end{array}$ & $20 \%$ \\
\hline 2. & $\begin{array}{c}\text { Diagrammatic representation of } \\
\text { the problem }\end{array}$ & $20 \%$ \\
\hline 3. & $\begin{array}{c}\text { Identifying and computing data } \\
\text { needed to be applied in formula }\end{array}$ & $20 \%$ \\
\hline 4. & $\begin{array}{c}\text { Applying data in the formula and } \\
\text { solving using appropriate } \\
\text { technique }\end{array}$ & $30 \%$ \\
\hline 4. & Conclusion for the given problem & $10 \%$ \\
\hline
\end{tabular}

As this study is to measure the impact of smart board approach in teaching Engineering Mathematics II, the proportion of students whose marks are above $50 \%$ marks in their Continuous Assessment Test III and Assignment Test III is obtained from Sample I and Sample II. This proportion is analysed and studied using z-Test. As the sample size is 60 in both case, large sample test shall be applied. For zTests to be performed, the data should be distributed normally. As the data that supports our study is normally distributed, the above-mentioned test shall be performed.

\section{Results and Discussion:}

\section{A. Study on Sample I:}

The marks obtained by students in Continuous Assessment Test III (SI-CAT III) and Assignment III (SI-ASS III) is considered. They are found to be normally distributed. Fig:1 shows the normal curve of data under study.

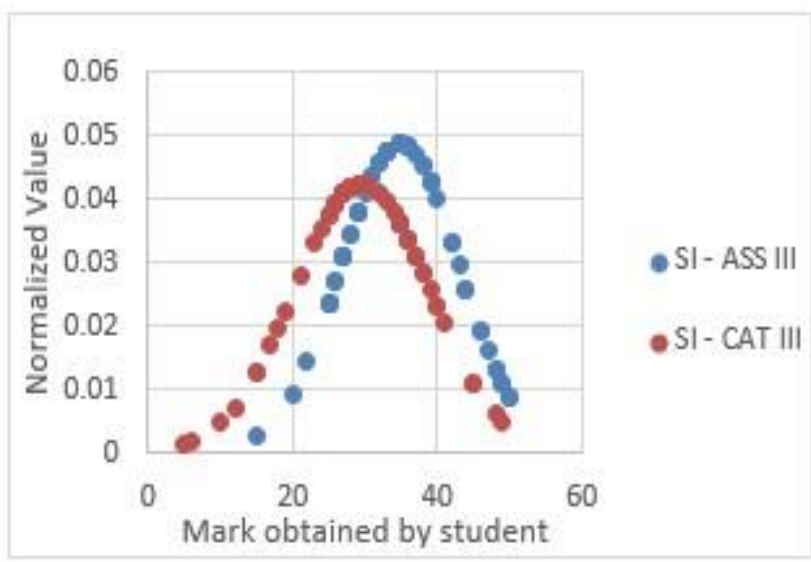

Fig. 1 Normal curve of Sample I - Assignment III Marks and Continuous Assessment Test III Marks

From the data, the proportion of students who scored above $50 \%$ in Continuous Assessment Test III, $\mathrm{P}_{\text {(SI-CAT III) }}$ and in Assignment III, $\mathrm{P}_{\text {(SI-ASS III) }}$ is obtained and is tabulated in Table:5. The null hypotheses are formulated as the proportion of students who secure above $50 \%$ marks in SI:CAT III and SI: ASS III is equal. The alternate hypothesis is formulated as $\left(\mathrm{P}_{\text {(SI: ASS III) }}-\mathrm{P}_{\text {(SI:CAT III) }}>0\right)$ ). Here the $\mathrm{z}$-Test is right-tailed. The $\mathrm{z}$-value that is calculated from the sample data using test of difference of proportion. The calculated zvalue is used to compute p-value. For this study, the level of 
significance is chosen as 0.1 . The null hypothesis is rejected in favour of alternate hypotheses if $\mathrm{p}$-value $<0.1$. From Table:5, the p-value that corresponds to data under study is $0.0054<0.1$. This shows that the data provides significant evidence against null hypotheses favouring alternate hypotheses at $10 \%$ level of significance.

Table: 5 - Correlation for sample-1 data

\begin{tabular}{|c|c|c|c|}
\hline \multicolumn{3}{|c|}{ Sample I } \\
\hline & & p-value & $\begin{array}{c}\text { Correlation } \\
\text { between marks } \\
\text { (SI: ASS III and } \\
\text { SI:CAT III) }\end{array}$ \\
\hline 0.95 & 0.80 & 0.0054 & 0.7487 \\
\hline
\end{tabular}

Thus, under traditional black board approach, the proportion of students who score above $50 \%$ reduces in continuous assessment test when compared to assignment as they have copied assignment. As a result, the attainment level of these course outcomes in Continuous Assessment test decreases from the level attained in Assignment. This in turn affects Journal of Engineering Education Transformations, Volume

the attainment level of these course outcomes in summative exam adversely.

\section{B. Study on Sample II:}

The marks obtained by students in Continuous Assessment Test III (SII-CAT III) and Assignment III (SII-ASS III) is considered. They are found to be normally distributed. Fig:2 shows the normal curve of data under study.

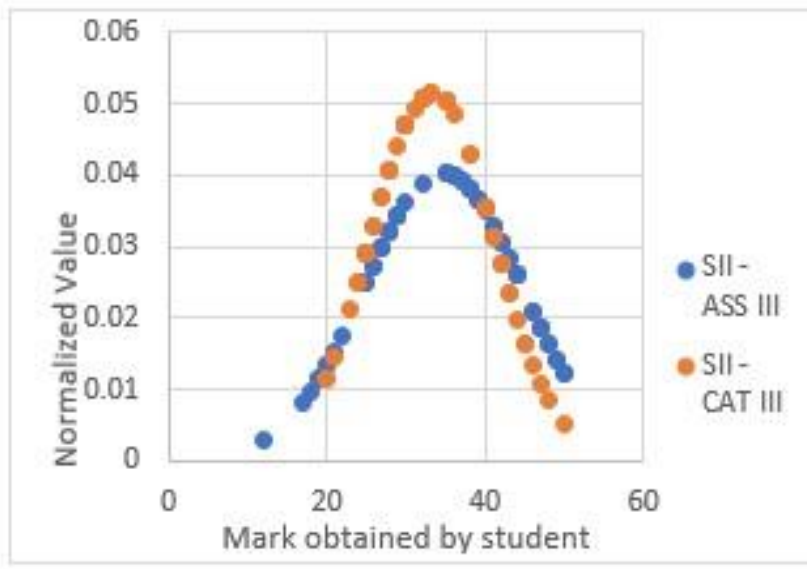

Fig. 2 Normal curve of Sample II - Assignment III Marks and Continuous Assessment Test III Marks

From the data, the proportion of students who scored above $50 \%$ in Continuous Assessment Test III, $\mathrm{P}_{\text {(SII-CAT III) }}$ and in Assignment III, $\mathrm{P}_{\text {(SII-ASS III) }}$ is obtained and is tabulated in Table:6. The null hypotheses are formulated as the proportion of students who secure above $50 \%$ marks in SI:CAT III and SI: ASS III is equal. The alternate hypothesis is formulated as (P(SI: ASS III) $\left.-\mathrm{P}_{\text {(SI:CAT III) }}<0\right)$. Here the $\mathrm{z}$-Test is left-tailed. The null hypothesis is rejected in favour of alternate hypotheses if p-value $<0.1$. From Table: 6 , the pvalue that corresponds to data under study is $0.0064<0.1$. This shows that the data provides significant evidence against null hypotheses favouring alternate hypotheses at $10 \%$ level of significance.

Table: 6 - Correlation for sample-1 data

\begin{tabular}{|c|c|c|c|}
\hline \multicolumn{4}{|c|}{ Sample II } \\
\hline $\begin{array}{c}\text { P(III: ASS } \\
\text { III) }\end{array}$ & $\begin{array}{c}\text { P(III:CAT } \\
\text { III) }\end{array}$ & $\begin{array}{c}\text { p-value } \\
\text { (lefttailed) }\end{array}$ & $\begin{array}{c}\text { Correlation } \\
\text { between marks } \\
\text { (SII: ASS III } \\
\text { and } \\
\text { SII:CAT III) }\end{array}$ \\
\hline 0.85 & 0.90 & 0.0064 & 0.8593 \\
\hline
\end{tabular}

Thus, under smart board approach, as copying assignment is restricted to great extent, this enables the learning ability of students thereby making students more efficient for their continuous assessment test. As a result, the proportion of students who score above $50 \%$ in Continuous Assessment Test tends to increase as their 2015, ISSN 2349-2473, eISSN 2394-1707

efficiency is improved through structured effective Assignments. Hence, the attainment level of the course outcomes under study in summative assessment does not deviate much from the attainment level in formative assessment.

\section{Study based on Correlation Coefficient:}

The correlation coefficient between the Assignment III and Continuous Assessment III marks of both the samples is calculated individually using Karl Pearson's Correlation Coefficient Method. From Table $5 \& 6$, the coefficient of correlation between the continuous assessment mark and assignment marks of Sample I is 0.7487 and that of Sample II is 0.8593. This gives an evidence that through Smart Board Approach, the marks obtained by students in assignment test and in continuous assessment test is quite strongly correlated when compared to traditional black board method. Also, from Fig:2, the scatter diagram reveals that the clustering of continuous assessment marks does not deviate much from assignment marks in case of slow learners. This indicates that the attainment level of these course outcomes shall gradually increase in smart board approach.

\section{Conclusion:}

Student-centric approach of learning plays a vital role in improving student's learning ability, efficiency, ability to reproduce, ability to apply the knowledge acquired to real time problems. All these attributes are quite well addressed and measured while using Smart Board rather than in using traditional black board, in student-centric approach. Students are greatly influenced by the innovative methods that are adopted while evaluating them in formative assessment. This study reveals that the performance of students in formative assessment is increased in a particular 
course outcome with the Smart Board approach, recommending its usage. This is in turn improves their performance in summative assessment. This study concludes that using Smart Board for content delivery and formative assessment for the unit Vector Calculus in Engineering Mathematics II influences student's performance positively in both formative and summative assessment. Innovation kindles student's attention. Smart Board is one that helps us to come up with lots of new strategy to pull student's interest for mathematics. This study has focused on a particular unit of the course. This study shall be extended in future to measure the impact on summative assessment of the entire course.

\section{References}

[1] Charoula Angeli (2004), "The effects of case-based learning on early childhood pre-service teachers' beliefs about the pedagogical uses of ICT", Journal of Educational Media, 29:2, 139-151.

[2] M. Prince (2004), "Does active learning work? A review of the research,” J. Eng. Educ., vol. 93, pp. 223-231.

[3] Heinze, A., Star, J., \&Verschaffel, L. (2009). Flexible and adaptive use of strategies and representations in mathematics education. ZDM- The International Journal on Mathematics Education, 41, 535-540.

[4] Katherine McKnight, Kimberly O'Malley, Roxanne Ruzic, Maria Kelly Horsley, John J. Franey \& Katherine Bassett (2016) Teaching in a Digital Age: How Educators Use Technology to Improve Student Learning, Journal of Research on Technology in Education, 48:3, 194-211

[5] Presmeg, N. (2006). Research on visualization in learning and teaching mathematics. In A. Gutierrez \& P. Boero (Eds.), Handbook of research on the psychology of mathematics education (pp. 205-235). Rotterdam: Sense Publishers.

[6] Tara J. Brigham (2013) Smart Boards: A Reemerging Technology, Medical Reference Services Quarterly, 32:2, 194-202

[7] Akar, H. (2020). The effect of smart board use on academic achievement: A meta-analytical and thematic study. International Journal of Education in Mathematics,

Science and Technology, 8(3), 261-273

[8] Blau, I. (2011). Being a smart teacher in a "smart classroom": Assessing teacher professional development for incorporating interactive White boards at schools.

Learning in the Technological Era, 63-74.
[9] Cabus, S. J., Haelermans, C., \& Franken, S. (2017). SMART in mathematics? Exploring the effects of inclass-level differentiation using SMART board on math proficiency. British Journal of Educational Technology, 48(1), 145-161.

[10] Davidovitch, N., \& Yavich, R. (2017). The effect smart boards on the cognition and motivation of students. Higher Education Studies, 7(1), 60.

[11] De Vita, M., Verschaffel, L., \& Elen, J. (2018). Towards a better understanding of the potential of interactive whiteboards in stimulating mathematics learning. Learning Environments Research, 21(1), 81-107.

[12] Villavicencio, F. T., \& Bernardo, A. B. (2016). Beyond math anxiety: Positive emotions predict mathematics achievement, self-regulation, and self-efficacy. The Asia-Pacific Education Researcher,25(3), 415-422.

[13] Linda Darling-Hammond, Lisa Flook, Channa CookHarvey, Brigid Barron \& David Osher (2020)

Implications for educational practice of the science of learning and development, Applied Developmental Sciene, 24:2, 97-140

[14] L R. Lattuca, I. Bergom, and D. B. Knight (2014), "Professional development, departmental contexts, and ue of instructional strategies," J. Eng. Educ., vol. 103, no. 4, pp. 549-572.

[15] P. D. Leedy and J. Omrod (2005), Qualitative Research. Englewood Cliffs, NJ, USA: Prentice-Hall. 